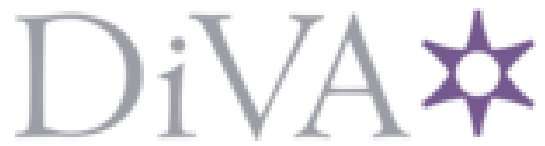

http://www.diva-portal.org

Preprint

This is the submitted version of a paper presented at 16th International Conference on European Energy Market (EEM).

Citation for the original published paper:

Herre, L., Tomasini, F., Paridari, K. (2019)

Optimal Day-Ahead Bidding of a Risk-Averse Pulp and Paper Mill in the Energy and Reserve Market

In: IEEE (ed.), (pp. 1-5). Ljubljana

N.B. When citing this work, cite the original published paper.

Permanent link to this version:

http://urn.kb.se/resolve?urn=urn:nbn:se:kth:diva-259643 


\title{
Optimal Day-Ahead Bidding of a Risk-Averse Pulp and Paper Mill in the Energy and Reserve Market
}

\author{
Lars Herre, Federica Tomasini and Kaveh Paridari \\ Division of Electric Power and Energy Systems \\ School of Electrical Engineering and Computer Science \\ KTH Royal Institute of Technology \\ 11428 Stockholm, Sweden \\ Email: $\{$ lherre, tomasini, paridari\}@kth.se
}

\begin{abstract}
Due to increased use of variable renewable energy sources, more capacity for reserves is required. Non-generating resources such as large industrial consumers can arbitrage energy prices and provide reserve capacity by exploiting the inherent flexibility in selected industrial processes. A large enough industrial consumer can capitalize on this flexibility through optimized bidding in electricity markets. In this work, the day-ahead cost minimization of a risk-averse pulp and paper mill (PPM) is formulated as a two-stage stochastic problem, considering thermodynamic and electrical constraints of the PPM. The bids in the energy and reserve markets are optimized subject to price uncertainty. The results of a case study in Sweden display a significant economic benefit in exploiting the flexibility of PPM. The expected cost of the pulp and paper mill resulting from different strategies are compared and the risk adversity of the PPM is investigated. We show that reserve offers can significantly improve the profitability of the PPM.
\end{abstract}

Index Terms - demand side management, electricity markets, frequency containment reserve, industrial demand response.

\section{INTRODUCTION}

The Nordic TSOs recognize in Demand Response (DR) one of the most promising solutions to the current challenges that the power system is facing [1]. According to [2], Sweden can count on about $4,500 \mathrm{MW}$ of flexible demand; about $51 \%$ of it lies in the industrial sector. Energy intensive industries are the ones that are expected to play a more determining role. Not only they are the ones that could contribute with the greatest capacity, but also they are the ones that would experience an higher economic benefit, being the most affected by electricity cost variations [3]. Within the Swedish energy intensive industries, the Pulp and Paper firms are responsible for about $52 \%$ of the whole energy consumption, reason why, the Swedish Energy Agency affirms that changes in the sector's use of electricity have a significant impact on the total industrial electricity use [4]. A comprehensive review of DR applications in the industrial sector is provided in [5]. On this basis, the survey presents the contribution of ancillary services and their potential in industries and then introduces different types of industries with higher potential for DR programs. The $\mathrm{P} \& \mathrm{P}$ industry is classified as one with high potential for DR.

Marshman et al. [6] present an energy optimization algorithm for use in a pulp and paper mill cogeneration system, which uses steam for two purposes - to provide heat for the pulping process and to generate electricity for sale to regional providers. Santos et al. [7] develop a dispatch and investment model for production planning and scheduling problem occurring at an integrated pulp and paper mill (PPM). Figueira et al. [8] propose an optimization-based decision support scheme for a PPM, which extends on existing models by considering practical constraints and objectives. Rodriguez-Garcia et al. [9] show a simulation tool for industrial customers to perform a cost-benefit analysis regarding the implementation of Demand Response (DR) strategies, and exemplifies the potential of the paper manufacturing in DR programs as well as the benefits associated to it. Firm characteristics of the Swedish pulp and paper industry are studied by Lawrence et al. [10] and it is found that, for all types of mills, variation of electricity prices did not correlate significantly with energy efficiency during the study period.

The larger share of literature [6]-[10] has focused on improving the internal operation of the PPM and decreasing overall electricity consumption, i.e. energy efficiency. The concept of Demand Response (DR) is defined in [5] as the ability of power consumers to adapt their demand to the network's needs, possibly shifting demand to other periods. Only few references [11], [12] have studied the DR potential of a PPM with respect to optimized participation and bidding in wholesale electricity markets.

Those that analyzed the potential of DR in the P\&P industry identified the widest source of flexibility in the pulp production process, particularly in the refiners. According to Paulus et al. [11], the nominal capacity and the high utilization level of the machines rank them as the most promising ones for balancing services. Additionally, the authors identify in the availability of large pulp storage a resource that can ensure peaks shaving also on the day ahead market. Helin et al. [12] developed an optimization algorithm simulating the participation of some capacity from the refiner section to the regulating power market. This confirms that the highest potential is considered to be in the pulp production step. However, none of the above references mention the degradation of the quality of pulp as a consequence of a slowdown of the pulp production process. For this reason we excluded the refiners from the analysis in [13]. A lower quality of the pulp results inevitably in a worse quality of the paper. Here, however, we focus on the steam accumulator that can store steam containing thermal energy 
of up to $4 \mathrm{MWh}$ and thereby introduces a significant amount of flexibility to the production process.

\section{METHOD}

\section{A. Pulp \& Paper Production Process and Model}

The process begins with logs of spruce being debarked and chopped into chips. The material is stored in storage towers and transported to the pulp section when needed. Pulp can be produced by either chemical or thermo-mechanical pulping.

Refiners $(R E)$ : Here, the refiners are producing thermomechanical pulp. The process starts by a stream of wood chips entering the refiners. The refiners contain two counterrotating grooved metal disks that (due to strong centrifugal force) canalize the chips towards the edges of the disks while extracting the fibre contained in the wood. This process is responsible for around $70 \%$ of the whole energy consumption in the mill since substantial amounts of energy are dissipated in friction. Around $60 \%$ of the electricity consumed by the refiners is transformed into thermal energy in the form of low pressure steam. Due to the high temperature inside the refiners, the water contained inside the wood chips evaporates under low pressure. In a heat-exchanger, the energy of this 'dirty' steam is then used to produce clean steam that is further used in the paper machines.

Bleaching: The pulp passes through a series of cleaning and bleaching steps that improve its quality according to the individual requirements of the client. Bleaching is a chemical process that does not require significant amounts of electric energy.

Pulp Tanks: The pulp can be stored in pulp tanks before further use in the paper machines. When the pulp is needed, it is pumped to the so called wet end of the paper machine.

Electric Boilers $(B)$ : If the steam produced by the refiners is not sufficient for the drying process (e.g. during maintenance or fault), two large electric boilers can be quickly activated in order to compensate for the loss of hot steam. The two independent boilers have an electric rating of $60 \mathrm{MW}$ and 40 MW respectively. The steam produced by the boilers can then be stored in the accumulator, used in the paper machines, or spilled.

Steam Accumulator (A): In the studied PPM a steam accumulator is present, that stores pressurized saturated liquid at up to 13 bar with a flexibility of $4 \mathrm{MWh}$ thermal energy (enthalpy corresponding to thermal energy between 6 to $10 \mathrm{MWh}$ ).

Auxiliary 10 bar grid $(C)$ : From the steam accumulator, a constant amount of steam is pressurized to 10 bar and used for auxiliary processes in the 10 bar grid.

Spillage $(S)$ : If too much steam has been produced, it can be spilled from the low pressure bar.

Paper Machines (PM): The paper machines make use of the 'cleaned' steam from the refiners, the additional steam from the electric boilers, and potential steam being released by the steam accumulator. The wet end begins with a dewatering step. A wide and flat nozzle sprays the wet pulp on a fine, rotating net that transports the material to the pressing section. Here, more water is lost and the thickness of the end product is adjusted. Then the sheet passes through the drying section, where the - now 'clean' - steam is used to remove all remaining water in the paper. The paper is now ready to be rolled up into reels that are cut to satisfy a given client order.

Identification of Flexibility: The loads with highest flexibility were found in the electric boiler and steam accumulator. The power capacity of the electric boilers can only be exploited since it is supported by the energy capacity of the steam accumulator and the option of steam spillage. The electric boilers can ramp to full power within seconds and are extremely fast to adjust power consumption into both directions (up- and downwards). The electric rating of $(60+40)$ MW displays a significant potential of power capacity. The steam accumulator had been installed as a backup, in order to avoid steam shortages in extreme cases where neither the refiners nor the boilers can provide the required steam. However, it can also be used as a thermal energy storage of $4 \mathrm{MWh}$.

\section{B. Nordic Electricity Market and Primary Reserve Markets}

In this paper, we examine a PPM that participates in the day-ahead energy and reserve market, and - being a BRP implicitly in the imbalance settlement. The PPM can place bids in the following markets who are referred with their superscripts as below.

$D A$ : The day-ahead energy spot market where energy $e_{t}^{D A}$ is purchased at price $\lambda_{t}^{D A}$ at hour $t$.

$R T$ : Imbalance settlement for real-time energy consumption. A one-price consumption imbalance settlement [14] is assumed where the PPM pays $\lambda_{t}^{R T}$ for deviation of the real-time consumption $e_{t}^{R T}$ from the DA purchase.

$R$ : Frequency containment reserve in normal operation (FCR-N), i.e. primary frequency regulation, where capacity $p_{t}^{R}$ is remunerated with $\lambda_{t}^{R}$.

$I$ : Imbalance fee $\lambda^{I}$ that penalizes uninstructed energy deviations from the DA bids in real-time.

The total cost of the PPM at hour $t$ is thus

$$
e_{t}^{D A} \cdot \lambda_{t}^{D A}+\left(e_{t}^{R T}-e_{t}^{D A}\right) \cdot\left(\lambda_{t}^{R T}+\lambda_{t}^{I}\right)-p_{t}^{R} \cdot \lambda_{t}^{R} \quad \mathrm{SEK}
$$

\section{Assumptions}

Fig. 11 shows the simplified plant scheme. Electric power $p$ and energy $e$ are indicated in blue, steam from different pressure levels is converted to the thermal energy $q$ in time interval $\Delta t$ in red, and mass flows are highlighted in green. The following set of assumptions facilitates the derivation of a simplified PPM model [13] illustrated in Fig. 1]

- We represent steam by the thermal energy contained in its mass flow per hour. Given temperature, pressure and enthalpy of saturated steam, we obtain the thermal energy contained in the hourly steam flow $q$ and disregard losses related to expansion of steam (isenthalpic process).

- The electric boilers can be controlled instantaneously.

- The daily production rates for the next day are known.

- The daily income from paper sale is constant. 


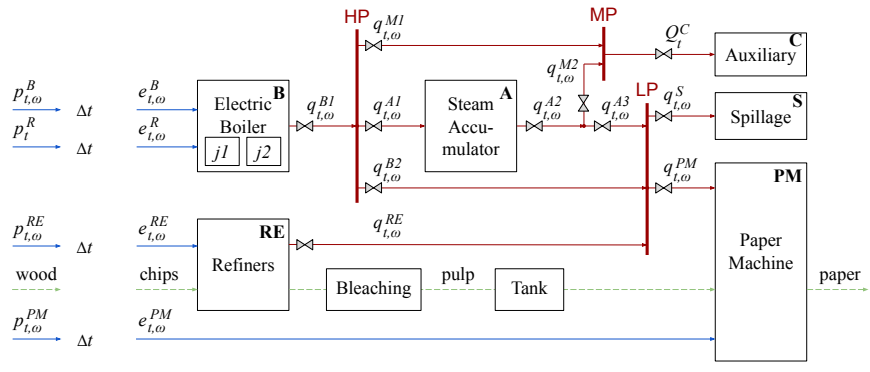

Fig. 1. Simplified plant scheme of a pulp \& paper mill (from [13]) in Sweden. Electric power $p$ and energy $e$ are indicated in blue, steam from different pressure levels is converted to the thermal energy $q$ in time interval $\Delta t$ in red, and mass flows are highlighted in green.

- The PPM has perfect forecasts of energy and reserve prices.

- The PPM can be modeled as a price taker.

- There is no minimum bid size. Energy and reserve bids are accepted at the marginal system price.

- Reserve bids are compensated for power capacity, irrespective of the actual real-time energy activation.

- The real-time activation of reserve energy is well represented by hourly mean values of the frequency.

\section{Problem Formulation}

We formulate the cost minimization of the risk-averse PPM as a two-stage stochastic problem in [13] with price uncertainty for RT prices and frequency realizations. The objective of the PPM is to minimize the weighted sum of expected cost $\mathbb{E}\left[c_{\omega}^{T}\right]$ and the conditional value at risk $(\mathrm{CVaR})$,

$\min . \quad(1-\beta) \cdot \mathbb{E}\left[c_{\omega}^{T}\right]+\beta \cdot \mathrm{CVaR}$

s.t. $\mathbb{E}\left[c_{\omega}\right]=c^{D A}-c^{R}+\sum_{\omega \in \Omega} \pi_{\omega}\left(c_{\omega}^{R T}+c_{\omega}^{I}+c_{\omega}^{X}\right)$,

Cost and revenues, Operational penalties,

Electric power \& energy constraints, Steam balance,

Start-up \& shut-down of el. boilers, Production limits,

Accumulator balance, Line limits, Risk-aversion

with risk-aversion weight $\beta \in(0,1)$. The PPM places bids on the DA energy market and the reserve market on the dayahead. Therefore, we consider the cost from energy purchased in the DA market $c^{D A}$, and the income from FCR-N reserve capacity $c^{R}$ as first-stage decisions.

In the real-time operation, the reserve power is activated based on a stochastic frequency signal. The real-time (RT) energy imbalance settlement price is announced ex-post and thus also a stochastic parameter. The costs that are dependent on second stage decisions are weighted by the respective probability $\pi_{\omega}$ of scenario $\omega$. The cost (or revenue) of realtime imbalance energy purchase (or sale) is captured by $c_{\omega}^{R T}$. The penalty for uninstructed energy imbalance is $c_{\omega}^{I}$. The last term $c_{\omega}^{X}$ captures penalty terms for steam accumulator end state, steam spillage and start-up costs of boilers.
TABLE I

DEFINITION OF THE FIVE SUMMER AND WINTER CASES

\begin{tabular}{ll}
\hline Case & Description \\
\hline 1 Reference & w/o Accumulator, w/o Reserve Provision \\
2 Energy Optimization & w/ Accumulator, w/o Reserve Provision \\
3 Energy \& Reserve & w/ Accumulator, w/ Reserve Provision \\
4 No Accumulator & w/o Accumulator, w/ Reserve Provision \\
5 No Spillage & high spillage penalty $5000 \frac{\text { SEK }}{\mathrm{MWh}}$ \\
\hline
\end{tabular}

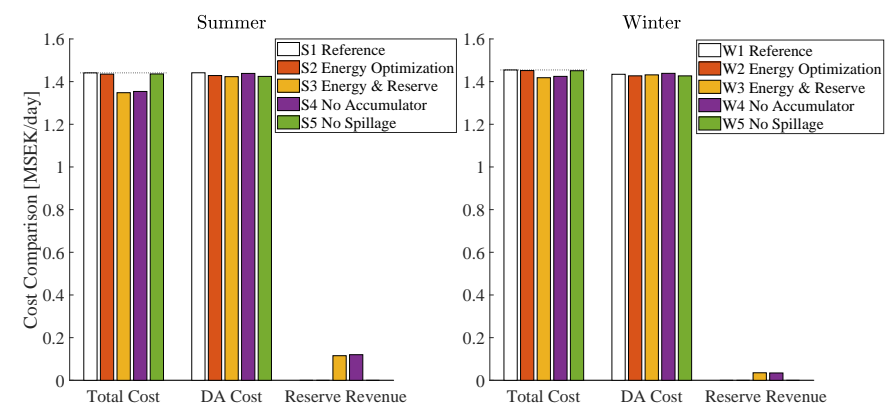

Fig. 2. Cost comparison of case studies in terms of total expected cost, day-ahead cost for energy purchase, and revenue from reserve capacity.

\section{RESULTS}

The model is applied to a risk-averse $(\beta=0.6)$ PPM with historical price and frequency scenarios in price area SE3 in Sweden. The energy market related parameters are public data; hourly energy price data is available from Nord Pool [15] and reserve prices from Mimer [16]. The historical frequency data is available from Fingrid [17]. The PPM related data was obtained from a PPM in Sweden. We model real-time imbalance settlement prices and frequency realizations with 300 scenarios in summer and winter respectively.

The input parameters for the case study are summarized in Table I. Case 1 represents today's business as usual as the reference case where a constant quantity of electricity is purchased, no optimization is run, and the accumulator is not utilized for flexibility. Case 2 describes energy arbitrage, when the PPM only optimizes their DA energy bids and realtime consumption where the objective is to exploit differences between energy prices in different hours. Case 3 describes a PPM that jointly optimizes energy and reserve bids. Case 4 models a PPM that jointly optimizes energy and reserve bids, but does not use a steam accumulator. Case 5 models a PPM that jointly optimizes energy and reserve bids, and strives to avoid steam spillage.

The resulting total cost, DA cost and reserve revenue are presented in Fig. 2 Cost Savings can be achieved in all cases, and are generally higher in summer. This can be largely attributed to higher reserve prices and resulting revenue during summer. In summer, $0.4 \%$ can be save in case 2 and 5, 6.5\% in case 3 and $6.0 \%$ in case 4 .

The results of the summer cases S2 to S5 are presented in Fig. 3 The results in case of energy arbitrage are presented 


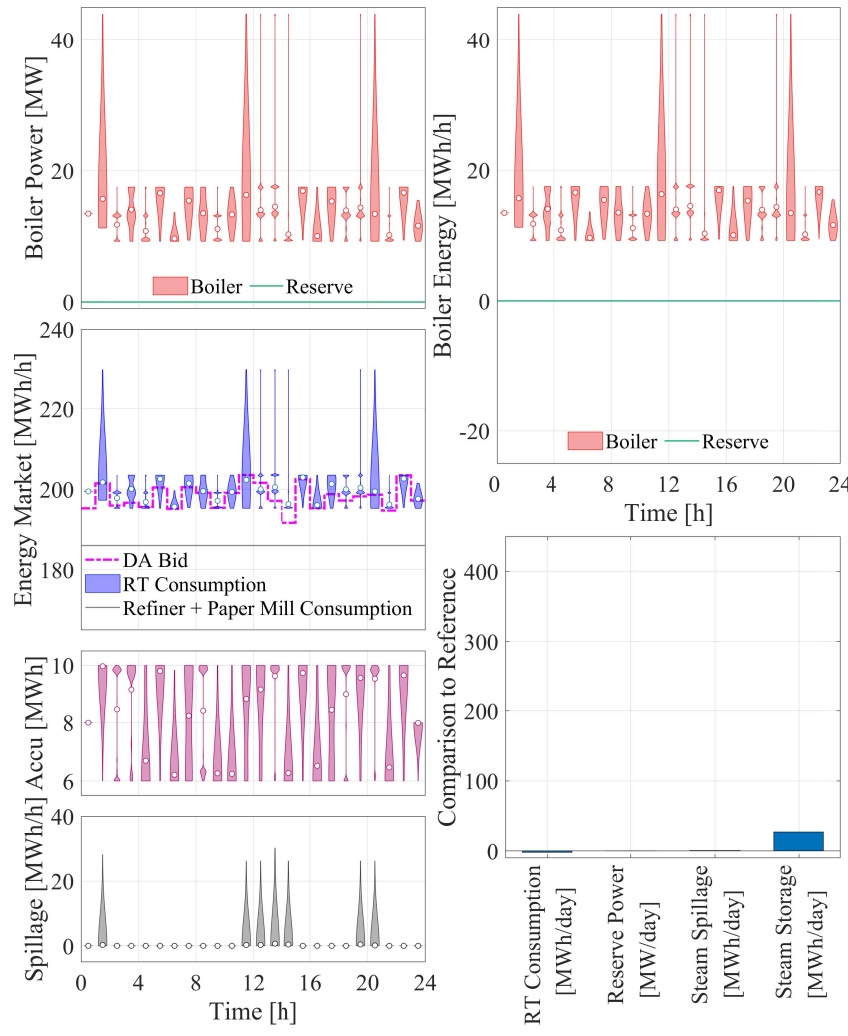

(a) S2 Only Energy Optimization
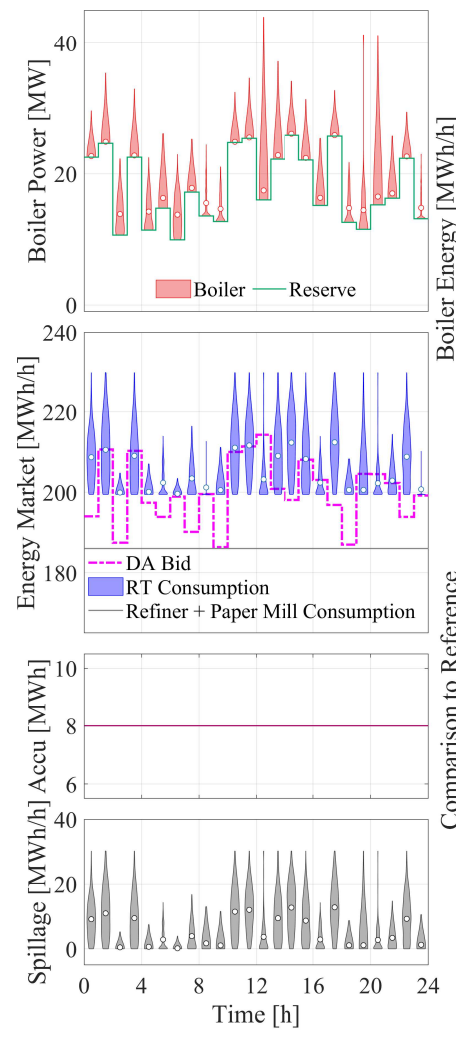

(c) S4 Energy \& Reserve Optimization: No Accumulator

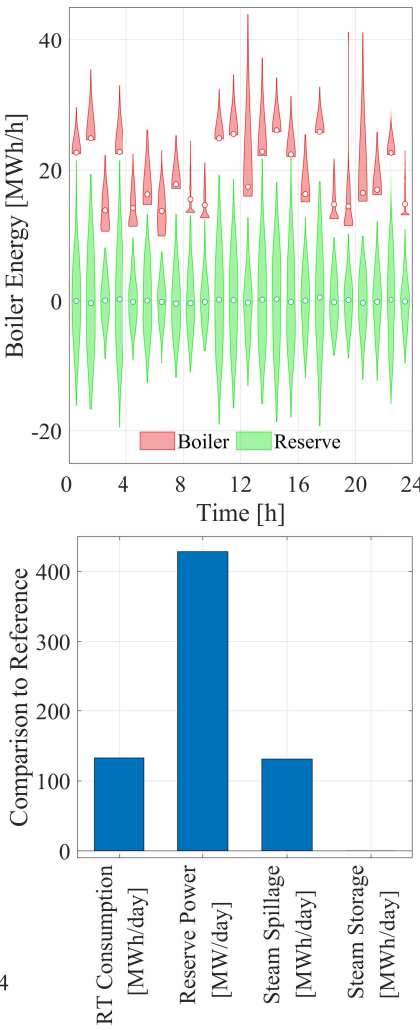

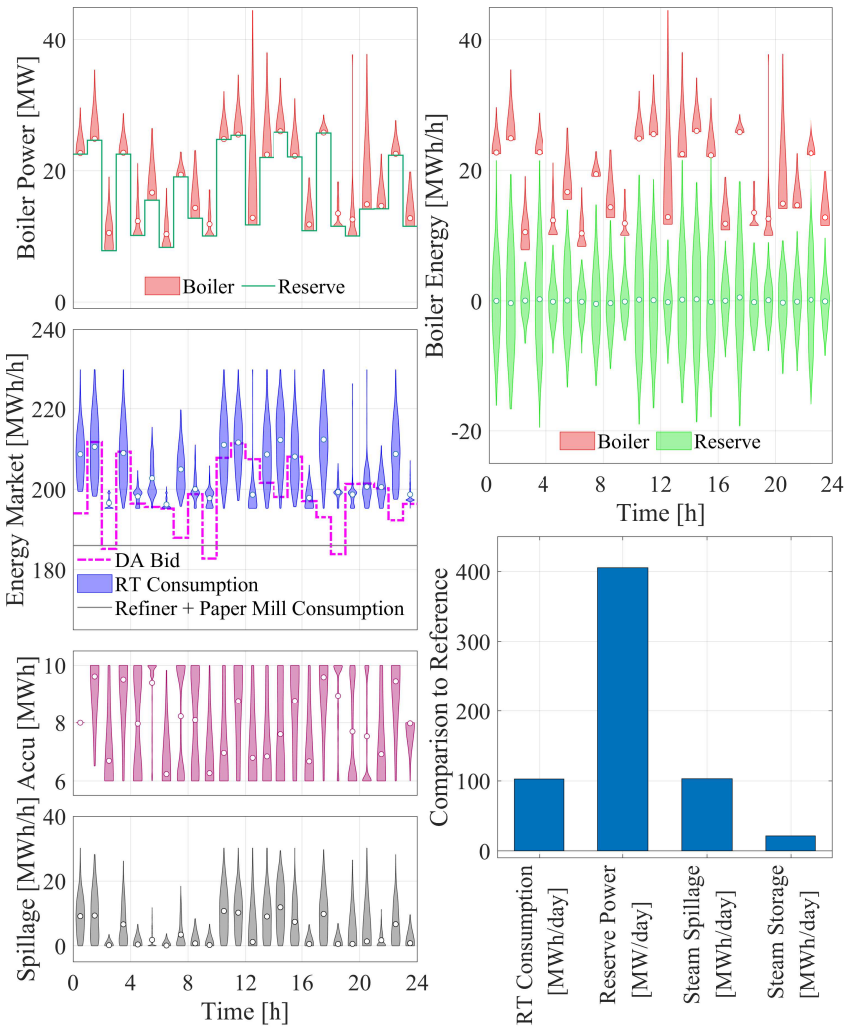

(b) S3 Energy \& FCR Optimization

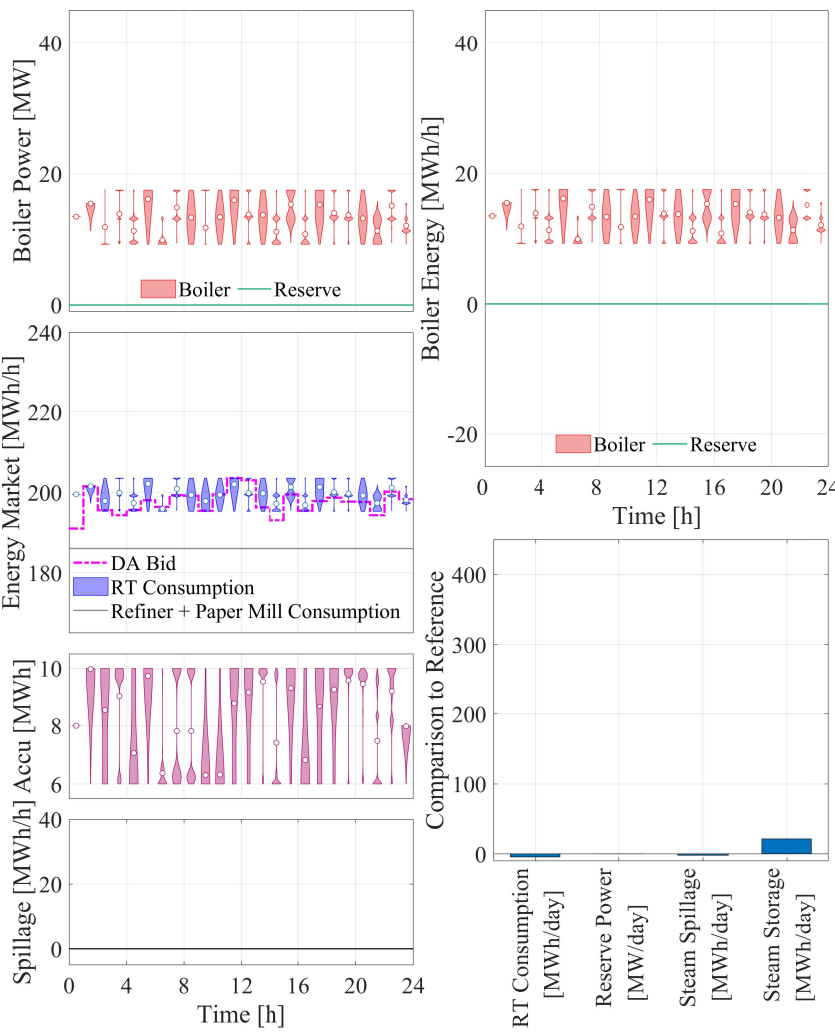

(d) S5 Energy \& Reserve Optimization: No Spillage

Fig. 3. Results of selected summer cases. Violin plots show the probability density of second-stage decisions while white dots show the expected value. 
in Fig. 3a. The violin plots illustrate the probability density of second-stage decision depending on the scenario and the dots point out the expected value. The top left graph shows that the power of the electric boiler is modulated extensively depending on the outcome of the RT prices, while no reserve power is provided. Below, the bids in the energy market are shown. The DA bid varies between 192 and $203 \mathrm{MWh} / \mathrm{h}$, while the RT consumption is at least $195.3 \mathrm{MWh} / \mathrm{h}$. Together with $4 \mathrm{MWh}$ from the steam accumulator this fulfills the minimum energy and steam requirement of the PPM. The steam accumulator is used heavily depending on the scenario and is expected at $50 \%$ at the end of the day. In the few scenarios where the total consumption exceeds $204 \mathrm{MW}$, the electric boilers consume additional energy and the excess steam is spilled. This is only economical in a one-price imbalance settlement system at those times when the system is down-regulating, requires demand to up-regulate and $\lambda_{t}^{R T}<\lambda_{t}^{D A}-\lambda^{I}$. The expected steam spillage is rather low throughout the day, and only increases in those scenarios where the boiler consume excessive energy. In the top right graph, the RT energy consumption in the boiler is shown. In the bottom right bar graph the daily RT consumption, reserve capacity, spillage and stored steam are compared with respect to the reference case.

The results in case of joint energy and reserve optimization are presented in Fig. 3b A total of $406 \mathrm{MW}$ of reserve power capacity is offered throughout the day, while the expected value of the activated energy for reserves is close to zero. The additional reserve bids and their stochastic activation, and excessive energy consumption in the boiler leads to even higher spillage.

Fig. 3c shows the results in case of joint energy and reserve optimization, where the accumulator is excluded. The reserve provision is of similar magnitude and even marginally higher.

When spillage is not allowed, but the accumulator is used, the results are shown in Fig. 3d The DA energy bidding strategy becomes more conservative and no reserves are provided. In this case, the flexibility of the accumulator is only used to arbitrage energy prices, but not to provide reserves.

\section{DISCUSSION}

In this case study, steam spillage poses as the main enabler of flexibility in terms of reserve capacity. The fast acting electric boilers provide the flexibility, and the spillage enables a high range of power consumption in the electric boiler without impacting the steam grid of the PPM. At first glance, this result seems unintuitive since spilling energy is against all energy efficiency measure. However, the main problem with renewable energy integration is not one of energy but of power capacity.

\section{CONClusion}

In this paper, we applied a simplified model of a Pulp-\& Paper Mill (PPM) for optimal day-ahead bidding in electricity and reserve markets considering risk-aversion. We demonstrate the applicability of the proposed simplified PPM model for day-ahead bidding purposes under uncertainty. Uncertainty is assumed in imbalance settlement prices and in real-time frequency realization (as hourly averages).

The operational cost savings are expected around 6.5\% which translates to 93,000 SEK per day. We find that the steam accumulator provides flexibility for energy arbitrage, but is not essential for providing reserve capacity and plays a minor role for cost savings. On the contrary, we show that the fast acting electric boiler together with steam spillage constitutes a major flexibility source for reserve capacity and cost savings.

\section{REFERENCES}

[1] "Challenges and Opportunities for the Nordic Power System," Statnett, Tech. Rep., 2016.

[2] L. Söder, P. D. Lund, H. Koduvere, T. F. Bolkesjø, G. H. Rosseb $\varnothing$, E. Rosenlund-Soysal, K. Skytte, J. Katz, and D. Blumberga, "A review of demand side flexibility potential in Northern Europe," Renewable and Sustainable Energy Reviews, vol. 91, no. March, pp. 654-664, 2018.

[3] "Measures to increase demand side flexibility in the Swedish electricity system," Swedish Energy Markets Inspectorate, Tech. Rep., 2017. [Online]. Available: https://www.ei.se/PageFiles/308322/Ei\{_\}R2017\{_ \}10.pdf

[4] Swedish Energy Agency, "Energy in Sweden (2017)," Swedish Energy Agency, Tech. Rep., 2018. [Online]. Available: https: //energimyndigheten.a-w2m.se/

[5] M. H. Shoreh, P. Siano, M. Shafie-khah, V. Loia, and J. P. Catalão, "A survey of industrial applications of Demand Response," Electric Power Systems Research, vol. 141, pp. 31-49, 2016.

[6] D. Marshman, T. Chmelyk, M. Sidhu, R. Gopaluni, and G. Dumont, "Energy optimization in a pulp and paper mill cogeneration facility," Applied Energy, vol. 87, no. 11, pp. 3514-3525, 2010.

[7] M. O. Santos and B. Almada-Lobo, "Integrated pulp and paper mill planning and scheduling," Computers \& Industrial Engineering, vol. 63 no. 1, pp. 1-12, 2012.

[8] G. Figueira, P. Amorim, L. Guimarães, M. Amorim-Lopes, F. NevesMoreira, and B. Almada-Lobo, "A decision support system for the operational production planning and scheduling of an integrated pulp and paper mill," Computers \& Chemical Engineering, vol. 77, pp. 85104, 2015.

[9] J. Rodríguez-García, C. Álvarez-Bel, J.-F. Carbonell-Carretero, M. Alcázar-Ortega, and E. Peñalvo-López, "A novel tool for the evaluation and assessment of demand response activities in the industrial sector," Energy, vol. 113, pp. 1136-1146, 2016.

[10] A. Lawrence, M. Karlsson, and P. Thollander, "Effects of firm characteristics and energy management for improving energy efficiency in the pulp and paper industry," Energy, vol. 153, pp. 825-835, 2018.

[11] M. Paulus and F. Borggrefe, "The potential of demand-side management in energy-intensive industries for electricity markets in Germany," Applied Energy, vol. 88, no. 2, pp. 432-441, 2011.

[12] K. Helin, A. Käki, B. Zakeri, R. Lahdelma, and S. Syri, "Economic potential of industrial demand side management in pulp and paper industry," Energy, vol. 141, pp. 1681-1694, 2017.

[13] L. Herre, F. Tomasini, K. Paridari, and L. Söder, "A simplified model of a pulp-\& paper mill for optimal bidding in electricity wholesale markets and primary frequency reserve provision," Applied Energy submitted, 2019.

[14] eSett Oy Settlement Service, "eSett Handbook," 2018. [Online]. Available: https://www.esett.com/handbook/

[15] Nord Pool AS, "Historic Market Data," October 2018. [Online]. Available: http://www.nordpoolspot.com/historical-market-data/

[16] Svenska Kraftnät, "Mimer - Primary Regulation Prices." [Online]. Available: https://mimer.svk.se/PrimaryRegulation/PrimaryRegulationIndex

[17] Fingrid, "Fingrid - Open Data." [Online]. Available: https://data.fingrid. fi/en/dataset/frequency-historical-data 